\title{
Development of Aerodynamic Braking and Energy Recovery Systems for High-Speed Rail Transport
}

\author{
${ }^{1}$ Kisseleva Olga, ${ }^{1}$ Nussupbekova Gulzhan, ${ }^{1}$ Mamyrova Aisha, \\ ${ }^{2}$ Tulegenova Bakyt and ${ }^{3}$ Bissarinova Aigul \\ ${ }^{1}$ University Turan, Almaty, Kazakhstan \\ ${ }^{2}$ Kazakh National Research Technical University named after KI Satpayev, Almaty, Kazakhstan \\ ${ }^{3}$ International Information Technology University, Almaty, Kazakhstan
}

\begin{abstract}
The reviewed concept describes aerodynamic braking and recuperation of kinetic energy for high-speed railway transport. It demonstrates all advantages in using the aerodynamic method of braking and recuperation of kinetic energy of railway transport moving at speed over $100 \mathrm{~km} / \mathrm{h}$. It illustrates the implementation system of aerodynamic method of braking and recuperation of kinetic energy of railway transport and outlines basic disadvantages and prospectives for the concept development.
\end{abstract}

$\underline{\text { Key words: Aerodynamic, recuperation, kinetic energy, transport, implementation system, development }}$

\section{INTRODUCTION}

For the past 150 years, the rail mileage on the Earth has been increasing and now reached enormous values. Contemporary train speed exceeds $100 \mathrm{~km} / \mathrm{h}$. Despite that fact the traditional technology of railway train braking is still in use. This technology consists of brake shoe pressure to wheel sets. Depending on the landscape this may lead up to $30 \%$ of energy loss on railway train braking. In addition to that, emergency braking leads to heavy and irregular wear of brake shoes, rails and wheel sets. Emergency braking at high speed may also lead to dramatical results caused by sticking of wheel sets to brake shoes. Besides that, extra fuel consumption may also take place not only at acceleration or traction but also at braking.

The value of kinetic Energy $E$ for the train with the mass $m$ moving at the speed $v$ is $E_{c}=m \times v 2 / 2$. In case of abrupt brake application, all kinetic energy converts into the internal energy because of frictional force. This causes brake shoes heating along with wheel sets.

\section{MATERIALS AND METHODS}

Another method of deceleration applies drag energy $\mathrm{E}_{\mathrm{B}}$ of a moving train increasing towards the incoming air stream $\mathrm{E}_{\mathrm{B}}=\zeta \times v 3 \times \mathrm{S} / 2$ where $\zeta$ is the incoming air stream density and $S \pi$ is the aerodynamic drag area. The accurate calculation of $\mathrm{S} \pi$ for a train consisting of several carriages can be omitted (Howlett, 1996). Instead of it, the qualitative calculation of increase in aerodynamic drag Energy $\Delta \mathrm{E}_{\mathrm{B}}$ can be carried out. This means the result for the train surface area orthographic projection to the incoming air stream in case the train is equipped with $\mathrm{N}$ air intake elements. Each air intake Surface is $\mathrm{S}_{\mathrm{i}}$. Calculation of $\Delta \mathrm{E}_{\mathrm{B}}$ can be carried out as per following formula: $\zeta \times v^{3} \times \mathrm{N} \times \mathrm{S}_{\mathrm{i}}$ at $\zeta=1.25 \mathrm{~kg} / \mathrm{m}^{3}, v=33 \mathrm{~m} / \mathrm{sec}($ or $120 \mathrm{~km} / \mathrm{h}$ ), N $=200$ and $\mathrm{S}_{\mathrm{i}}=1 \mathrm{~m}^{2}$. The calculation result is $\Delta \mathrm{E}_{\mathrm{B}}=$ $1.25 \times 33^{3} \times 200 \times 1.0=8984[\mathrm{~J}]$ or $8984 \mathrm{~kW}$. This value is rather significant and its conversion into the internal energy (Liu and Golovitcher, 2003) would cause heating of axle boxes, rails and wheel sets for $8.984 \times 10^{3} \times 0.24=215$ $622 \mathrm{k} / \mathrm{cal}$ where $1 \mathrm{cal}$ is equal to $4.1868 \mathrm{~J}$.

Instead of accepting such useless and harmful consequences, this energy can be converted into the electric energy and applied for increase of train traction characteristics. The concept of such braking energy recuperation system is demonstrated in Fig. 1 .

The exterior of a carriage is equipped with built-in air intakes $\mathrm{K}_{1}, \ldots, \mathrm{K}_{\mathrm{m}}$ with their outlets directed to wind engines $B_{1}, \ldots, B_{m}$. Wind engines rotate electric Generators $\mathrm{G}_{1}, \ldots, \mathrm{G}_{\mathrm{m}}$ and generators are structurally combined with air intakes $\mathrm{K}_{1}, \ldots, \mathrm{K}_{\mathrm{m}}$. Electric outlets of Generators $\mathrm{G}_{1}, \ldots, \mathrm{G}_{\mathrm{m}}$ are connected with inlets $1, \ldots, \mathrm{M}$ of electric adder $\Sigma$. Adder's outlet is connected with a normalizer $\mathrm{H}$ and provides a necessary range of output voltage and power for all operation modes of electric Generators $G_{1}, \ldots, G_{m}$. Outlets of electric adder $\Sigma$ are connected via. the adaptive charge module (ACM on Fig. 1) to the inlets of the battery (BAT on Fig. 1). Outlets of the battery BAT are connected

Corresponding Author: Kisseleva Olga, Department of Computer and Software Engineering, University Turan, Almaty, Kazakhstan, ident06@mail.ru, +77073821012 
with a traction electric drive (TED on Fig. 1) of the carriage. Control for the traction elecric drive is provided from the main outlet of the control unit of braking energy recuperation subsystem. Additional outlets of the control unit provide control for air intakes $\mathrm{K}_{1}, \ldots, \mathrm{K}_{\mathrm{m}}$ position. In case carriage needs no braking the outer walls of air intakes $\mathrm{K}_{1}, \ldots, \mathrm{K}_{\mathrm{m}}$ are flush-mounted into the upper and side walls of the carriage and do not cause any drag effect. In this mode electric Generators $G_{1}, \ldots, G_{m}$ do not rotate and voltage and power for BAT charge are equal zero. Stored energy of BAT is spent on carriage traction by using the traction electric drive TED.

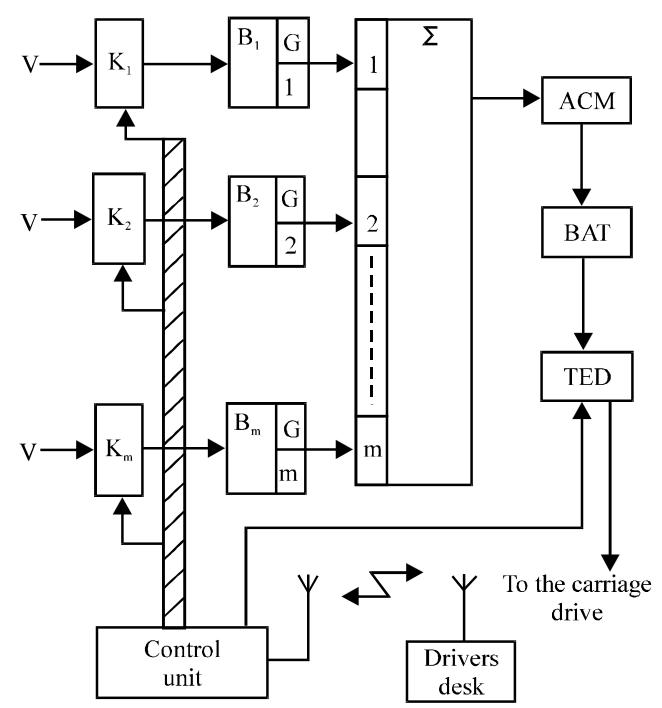

Fig. 1: The structure of braking energy recuperation system applied for railway carriages
Railway brake of the entire train or its part is carried out from the driver's desk. Signal from the desk is transmitted to control units of carriages using wireless transmit-receive devices. This signal sets air intakes $\mathrm{K}_{1}, \ldots, \mathrm{K}_{\mathrm{m}}$ into the mode of maximal aerodynamic drag and provides efficient braking of the train.

The well-known solution (Howlett et al., 2009) can be considered as the prototype of design for the compatible air intake. Outlets of air intakes carry out fast rotation of wind engines $B_{1}, \ldots, B_{m}$. Wind engines in turn, carry out rotation of electric Generators $G_{1}, \ldots, G_{m}$ a. Electric energy of generators is added in the electric adder $\Sigma$, flows through the normalizer $\mathrm{H}$ and $\mathrm{ACM}$ and used for the battery BAT charge.

The design of air intakes $\mathrm{K}_{1}, \ldots, \mathrm{K}_{\mathrm{m}}$ built into the deck and/or walls of the carriage is shown in Fig. 2 in a flush-mounted mode. Braking mode of operation for air intakes is shown in Fig. 3.

In case no braking is applied to the carriage, the position of the air intake is under the carriage deck 1 . In this case the air intake consists of the upper cover 2 with an elliptic protrusion 3 , axle fastener 4 of the cover 2 . The wind engine 6 is installed under the elliptic protrusion 3 on a shaft 5 and has freedom for angular rotation (not shown on Fig. 2). The right part of the deck 1 has louvers 7 which are closed while no braking. These louvers are assigned for air stream output from the wind engine 6. Besides the cover 2, the air intake set contains side fan-shaped sliding walls 8 . These walls are collapsed and pressed with the lower cover 9 of the air intake. The lower cover 9 is rigidly mounted to the carriage deck 1 .

During transition to the braking mode the left part of the cover 2 has the impact for opening over the deck of the carriage 1. Such impact can be achieved by using

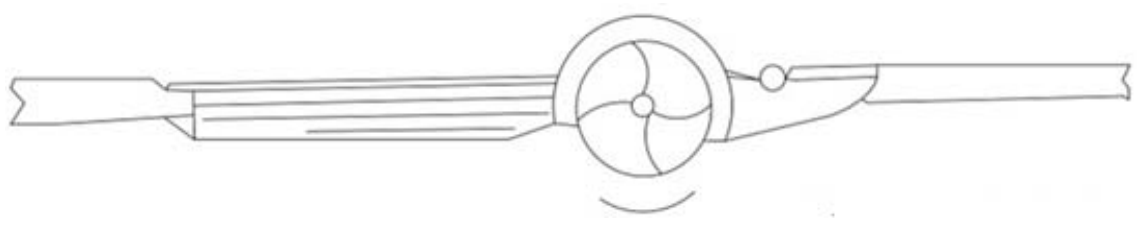

Fig. 2: Side drawing of the air intake in a flush-mounted mode of operation

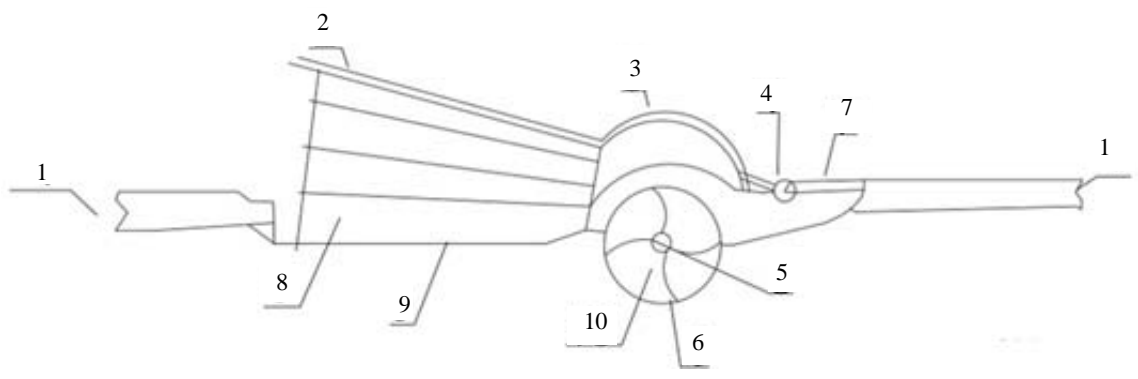

Fig. 3: Side drawing of the air intake in a braking mode of operation 
flexible pressure of side walls 8 to the cover 2 or the armature of a traction electric magnet or special pneumatic cylinder with the piston stroke range up to $50 \mathrm{~mm}$. Heavy air stream (Fig. 3) penetrates into the gap between the cover 2 and cover 1 and lifts the cover 2 up to its stop position. At the output of the air intake the air stream rotates the shaft 5 with blades 10 of the wind engine 6 . This provides high velocity clockwise angular rotation of the electric generator (not shown on Fig. 2 and 3). This generator has a kinematic connection with the shaft 5 . Air stream energy is converted into the electric energy and flows from electric generators outlets through the electrical adder for further storage into the carriage battery. The output air stream comes out of wind engines, dissipates through open louvers and collects by other air intakes in a traffic direction. Carriage length of $20 \mathrm{~m}$ enables the installation up to 11 air intakes on the carriage deck and up to 22 sets on side walls. The turbulence pattern of the airflow practically excludes its shielding from air intakes.

The aerodynamic drag of the carriage significantly increases due to protrusion of air intakes mounted on walls and cover of the carriage (Liu and Golovitcher, 2003). Consequently, this provides efficient braking with recuperation of braking energy and enables battery charge. In fact, the incoming airflow energy of all air intakes has cubed dependence of the carriage speed: $\Delta \mathrm{E}_{\mathrm{B}}$ $=\zeta \times v^{3} \times N_{B} \times S_{i}$ where $N_{B}$ is the quantity of air intakes applied for carriage braking. Figure 4 shows the dependency diagram for carriage braking energy and its speed. The horizontal axis contains the linear scale of the carriage speed (excluding velocity of the wind flowing within the carriage traffic area). For clarity sake, the vertical axis is made nonlinear. The dependency is calculated for the railway carriage equipped with 27 air intakes $\left(N_{B}=27\right)$. Each air intake airflow surface equals to $S_{i}=1 \mathrm{~m}^{2}$. In case of atmospheric density value $\zeta=1.25 \mathrm{~kg} / \mathrm{m}^{3}$ and carriage speed $v$ from 0 up to $110 \mathrm{~km} / \mathrm{h}$ for $v=100 \mathrm{~km} / \mathrm{h}$ the value of aerodynamic braking Energy $\Delta \mathrm{E}_{\mathrm{B}} \mathrm{w}$ ould be $456 \mathrm{~kJ}$ or $588 \mathrm{hp}$. These values are comparable with emergency brake application when brake shoes are also applied.

Considering the aerodynamic braking action (Fig. 4) can be divided into five typical ranges. Range I on Fig. 4 shows insignificant aerodynamic braking action (section $\mathrm{OB}$ ). Maximal carriage speed in this case is limited with 36 $\mathrm{km} / \mathrm{h}$. Range II demonstrates a low-level aerodynamic braking action between 36 and $55 \mathrm{~km} / \mathrm{h}$. Section CD can be described as the range of a moderate aerodynamic braking action at the speed between 55 and $70 \mathrm{~km} / \mathrm{h}$. In case the incoming air stream speed value lies between 70 and $100 \mathrm{~km} / \mathrm{h}$,section CD describes the effect which is

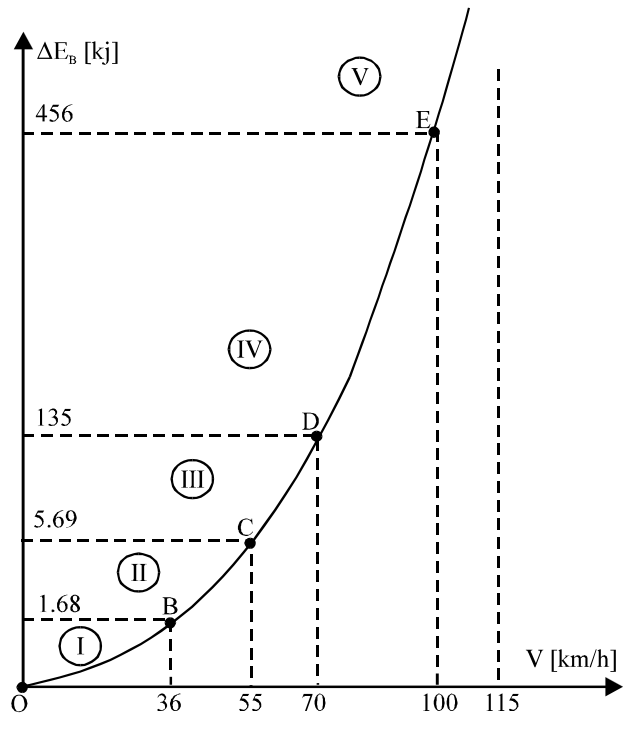

Fig. 4: Dependency diagram between carriage braking energy and its speed

comparable with conventional braking mechanism application. Range IV describes the average aerodynamic effect on the moving train.

Range V is typical for speed values over $100 \mathrm{~km} / \mathrm{h}$ and can be described as the area of a dominating aerodynamic action on the moving train. In this case application of this action is more preferable compared to conventional methods of braking.

In case of speed value exceeding $100 \mathrm{~km} / \mathrm{h}$ the application of aerodynamic method of braking has no alternatives because of its safety and energy efficiency. This method is applicable for both normal and emergency braking. For example, such systems are widely applied for airbuses braking (Foiadelli et al., 2006).

Application of brake shoes plays a secondary role if aerodynamic braking action if applied. The derating operation of brake shoes significantly reduces the wear of wheel pair, brake shoes and rails. Besides that, combined application of the conventional braking method and aerodynamic braking action reduces braking distance (Howlett et al., 2009). And presence of the traction electric magnet enables additional braking with the current of the carriage battery.

The performance of aerodynamic braking action can be set remotely from a driver's desk. There are several possible control signals such as:

- Complete braking of all carriages and application of all air intakes

- Partial braking. For example with right, left or top air intakes of all carriages 
- Partial braking applied on carriages which have even or odd index numbers

- Combined braking with aerodynamic braking methods and application of brake shoes along with setting the battery current from a traction electric drive

Algorithms for most efficient methods can be implemented with use of specific software assigned for control units of carriages.

The velocity of incoming air flow reduces along with train deceleration. Covers of air intakes 2 on the carriage deck 1 reach their stop positions (they fall on carriage deck 1) and for example become locked with magnet locks (not shown on figures). This is reached by using unbalanced mass which is relative to the shaft 4 . The conventional method of braking can be applied in order to reduce braking distance and time necessary for complete stop.

Besides the diesel engine unit of the train, acceleration mode can activate traction electric drives of the carriage. This mode reduces loading on the main traction drive of the train. Electric energy in storage batteries is consumed for carriage acceleration (Scarpellini et al., 2013). This reduces fuel consumption and loading on the main traction drive.

For sidewall air intakes it is possible to use the cushioning mechanism. This mechanism would enable complete bottoming of air intakes to carriage walls while reduction of incoming airflow.

Figure 5 shows the exterior of the railway carriage equipped with 12 air intakes at constant speed or standing mode. Figure 6 demonstrates braking mode of the same carriage.

Of course, the exterior of every carriage of such type has difference in comparison with other types of carriages. Deceleration over $10 \mathrm{~m} / \mathrm{sec}$ or $36 \mathrm{~km} / \mathrm{h}$ leads to insignificant effect of aerodynamic braking and external covers of air intakes can be retracted into the deck and sidewalls (Castro et al., 2012). As a result, the carriage looks quite typical. All components of the braking system such as air intakes, electrical generators, control unit,
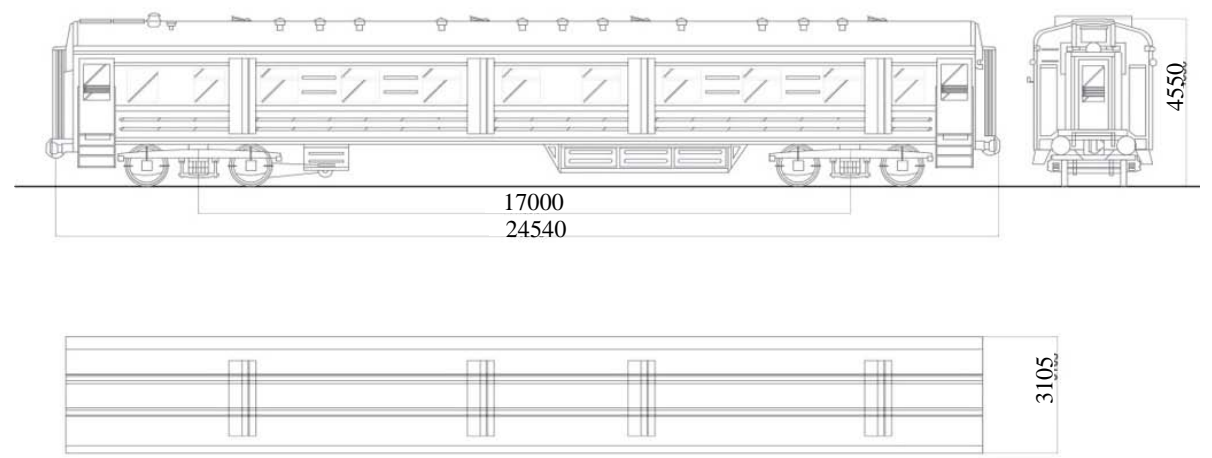

Fig. 5: Model exterior of the carriage at constant speed or standing mode

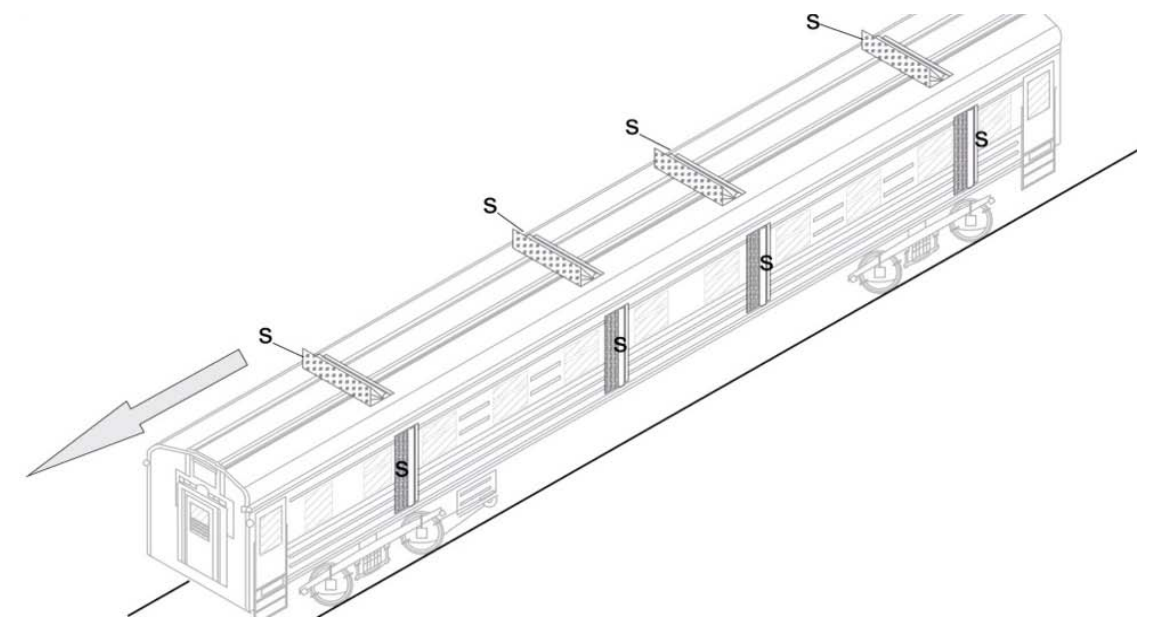

Fig. 6: Model exterior of the carriage with braking application 


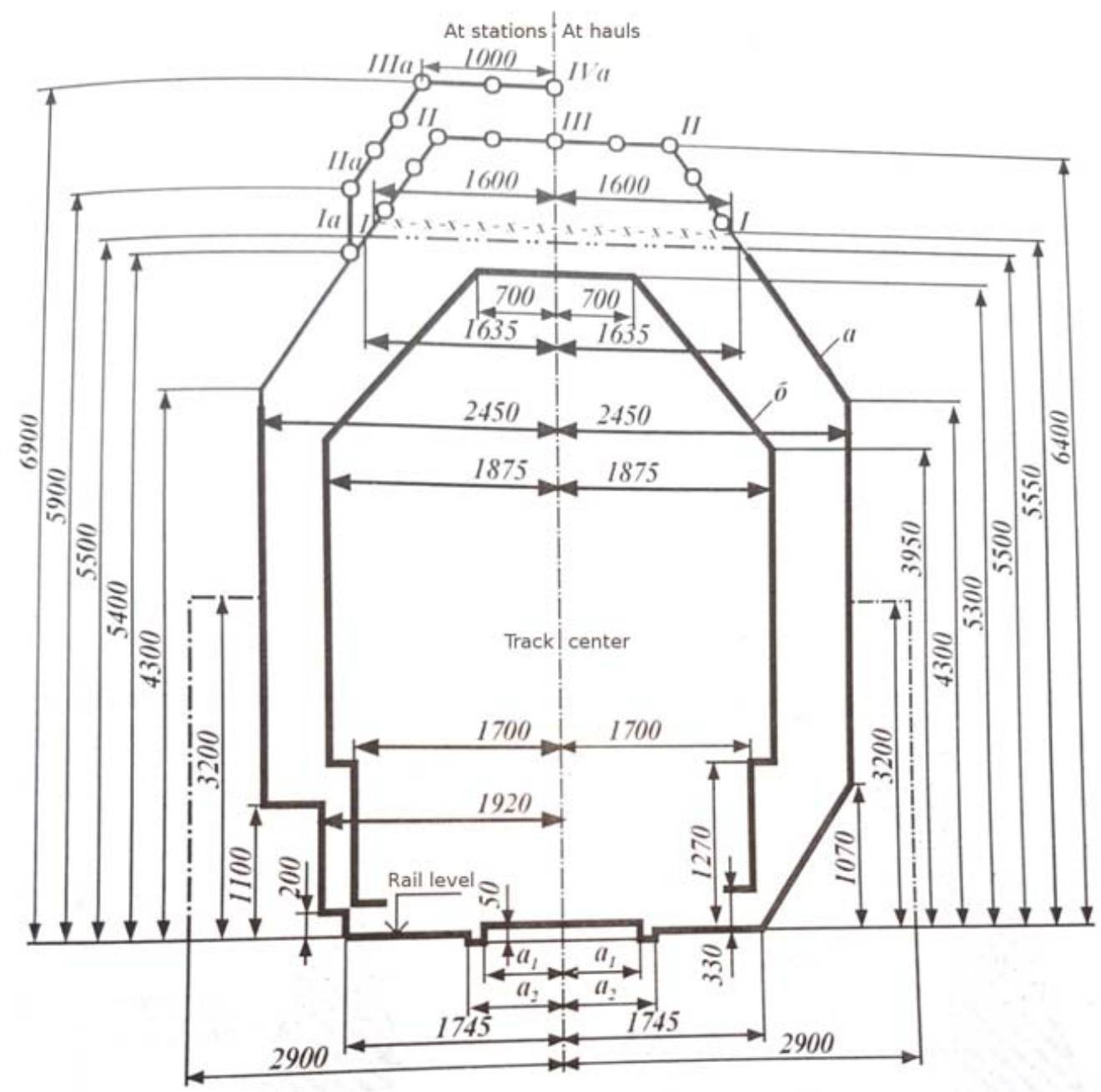

Combined dimensions: A-approximation of buildings C; b-rolling stock T; circuit I-II-II for span as well as tracks at stations (within artificial structures) on which rolling stock is not provided; circuit Ia-IIa-IIIa-Iva for the remaining paths of the stations; - $\mathrm{x}-\mathrm{x}-\mathrm{x}-\mathrm{for}$ paths whose electrification is excluded even with the electrification of this line; -... -... the upper loop of the approximation dimension Cn buildings, bel ow this line the outlines of dimensions $\mathrm{C}$ and $\mathrm{Cn}$ coincide. With gauge $1524 \mathrm{~mm}, \mathrm{a}_{1}=672 \mathrm{~mm}$ and $\mathrm{a}_{2}=762 \mathrm{~mm}$ with a track lenght of $1520 \mathrm{~mm} \mathrm{a}_{1}=670$ and $\mathrm{a}_{2}=760 \mathrm{~mm}$

Fig. 7: Combined dimensions of a carriage with $1524 \mathrm{~mm}$ gauge

electric batteries and traction electric driver can be installed inside the carriage below the deck and behind its walls. The possibility of equipment with protruding air intakes is substantiated with standards describing oversize areas for railway transport. Figure 7 (Fig. 4) demonstrates combined dimensions allowed for oversize trains. These dimensions can provide efficient braking and energy recuperation with air flows (Foiadelli et al., 2006).

\section{RESULTS AND DISCUSSION}

Calculated results of energy recuperation system application on the railway transport, demonstrated on
Fig. 4 are more than satisfactory (Klyuchev and Terekhov, 1980). All advantages and restrictions of the suggested concept for aerodynamic braking energy recuperation system are described below:

\section{Advantages:}

- Complete elimination of catastrophic situations during emergency brake application at high speed

- Significant increase in lifetime of wheel sets, brake shoes and rails due to more efficient integrated braking action using airflows

- Significant reduce of braking distance by using the conventional braking method in cooperation with the aerodynamic braking method 
- Significant reduce in fuel consumption necessary for acceleration and traction of railway trains and reached by using recuperation of kinetic energy during acceleration and deceleration

- Less time for acceleration due to using combined traction from the head section of the train along with traction drives of carriages

- Automatic control for deceleration process by adjustment of air intakes and combined use with a conventional deceleration system

\section{Restrictions:}

- New design of high speed railway carriages with air intakes mounted into walls and deck and has a kinematic connection with electric generators and wind engines

- Complicated design of absolutely new automation system assigned for control of recuperation and air intakes

- Requirement for areas of air intakes location and provision of safety fencing

- Requirement for additional equipment of carriages with traction electric drives, batteries and control units

- Requirement for additional equipment with wireless transmit-receive driver's desk and control units and provision of reliability level

- Requirement for carriage orientation in accordance with a train direction. Or design which would be invariant to the train direction

Prospectives of aerodynamic braking concept development for high speed railway transport: There are several ways for scientific and technological development of the present concept:

- Theoretical fundamentals of design for high speed trains equipped with systems of aerodynamic braking and recuperation of kinetic energy

- Design of systems equipped with automatic control for high speed trains with aerodynamic method of deceleration

- Design of power efficient systems assigned for kinetic braking energy recuperation in high speed railway transport

- Design of parts and devices assigned for aerodynamic braking and recuperation of kinetic energy in high speed railway transport

- Economics of design for high speed railway transport equipped with the aerodynamic braking system and system of kinetic energy recuperation

- Increase in reliability and safety of high speed railway transport equipped with aerodynamic braking system
- Design of hardware and software mechanisms for high speed railway transport equipped with aerodynamic braking system

\section{CONCLUSION}

Application of conventional braking systems for railway transport is connected with non-recoverable energy and fuel loss along with heavy wear of brake shoes, wheel sets and rails. Design and application of aerodynamic braking systems are more preferable for high speed railway transport from considering safety and power efficiency of railway transport.

The suggested design concept for aerodynamic braking and energy recuperation system provides significant lifetime increase for brake shoes, wheel sets, rails and provides fuel economy during acceleration, traction and deceleration. Implementation of the suggested concept is not possible for conventional design of carriages and requires for design of new carriage types. These types of carriages should have compatibility with the suggested recuperation system.

Implementation of the present concept has no insuperable design restrictions or problems. It is arguable to expect significant lifetime and safety increase in transport operation along with significant reduce in fuel consumption. This can be reached by implementation of suggested concept on the railway transport.

Implementation of the suggested system of aerodynamic braking and recuperation of kinetic energy on the railway transport acquires high priority in design of high speed railway trains.

\section{REFERENCES}

Castro, R.D., C. Pinto, R.E. Araujo, P. Melo and D. Freitas, 2012. Optimal sizing and energy management of hybrid storage systems. Proceedings of the 2012 IEEE International Conference on Vehicle Power and Propulsion, October 9-12, 2012, IEEE, Seoul, South Korea, ISBN:978-1-4673-0953-0, pp: 321-326.

Foiadelli, F., M. Roscia and D. Zaninelli, 2006. Optimization of storage devices for regenerative braking energy in subway systems. Proceedings of the 2006 IEEE International General Meeting on Power Engineering Society, June 18-22, 2006, IEEE, Montreal, Canada, pp: 1-6.

Howlett, P., 1996. Optimal strategies for the control of a train. Autom., 32: 519-532. 
Howlett, P.G., P.J. Pudney and X. Vu, 2009. Local energy minimization in optimal train control. Autom., 45: 2692-2698.

Klyuchev, I. and V.M. Terekhov, 1980. Electric Drive and Automation of Common Industrial Mechanisms. M.: Energy Research Institute, Russia,.
Liu, R.R. and I.M. Golovitcher, 2003. Energy-efficient operation of rail vehicles. Transp. Res. Part A. Policy Pract., 37: 91 7-932.

Scarpellini, S., A. Valero, E. Llera and A. Aranda, 2013. Multicriteria analysis for the assessment of energy innovations in the transport sector. Energy, 57: $160-168$. 